\title{
Relationship between FoxO1 protein levels and follicular development, atresia, and luteinization in the rat ovary
}

\author{
F Shi and P S LaPolt \\ Department of Biological Sciences, California State University-Los Angeles, 5151 State University Drive, Los Angeles, California 90032, USA \\ (Requests for offprints should be addressed to P S LaPolt; Email: plapolt@exchange.calstatela.edu)
}

\begin{abstract}
FoxO1 is a transcription factor implicated in a growing number of physiological processes, including apoptosis, cell cycle progression, and insulin signaling. Recent findings indicate that FSH and growth factors influence ovarian functions in part through regulation of FoxO1. The present study utilized immunohistochemical analysis to determine the ovarian localization and regulation of FoxO1 protein levels in neonatal rats, immature rats during gonadotropin-induced follicular development, ovulation, and luteinization, and in spontaneously developing ovarian cysts of aging rats. In postnatal rats, FoxO1 immunoreactivity was very faint in ovaries of 5- and 10-day-old females. In contrast, strong immunoreactivity was observed in granulosa cells of larger developing follicles at 25 days of age. To stimulate follicle development, immature female rats received equine chorionic gonadotropin (eCG) followed $52 \mathrm{~h}$ later by an ovulatory dose of human chorionic gonadotropin (hCG). Prior to gonadotropin treatment, moderate FoxO1 immunoreactivity was observed in granulosa cells of small follicles.
\end{abstract}

Subsequently, treatment with eCG markedly decreased FoxO1 protein levels in granulosa cells of healthy antral and preovulatory follicles. Interestingly, FoxO1 staining was observed in cumulus and antral, but not mural granulosa cells of preovulatory follicles. Induction of ovulation and luteinization with hCG further decreased ovarian FoxO1 levels, with no staining evident in corpora lutea. At all time points, the most intensive FoxO1 staining was observed in granulosa cells of atretic follicles, with predominantly nuclear localization. Similarly, while FoxO1 levels were low in granulosa cells of preovulatory follicles in proestrous rats, FoxO1 staining was intense in granulosa cells of spontaneously developing cystic follicles in aged, acyclic females. Together, these findings indicate that FoxO1 is expressed in a regulated, cell-specific manner during ovarian follicular development, atresia and luteinization, suggesting roles in these physiological processes.

Journal of Endocrinology (2003) 179, 195-203

\section{Introduction}

Ovarian functions are regulated by a number of hormones and autocrine/paracrine factors, acting through diverse signaling pathways. It is clear that the influences of gonadotropins on ovarian function are mediated, to a large part, through increased levels of the second messenger cAMP. While increased cAMP accumulation is known to activate protein kinase A (PKA)-dependent signaling, recent findings indicate that follicle-stimulating hormone (FSH)-stimulated cAMP may also activate protein kinase $\mathrm{B}(\mathrm{Akt} / \mathrm{PKB})$ in a PKA-independent manner (GonzalezRobayna et al. 2000), thus expanding the potential mechanisms through which gonadotropins act on ovarian cells. Among the substrates phosphorylated by Akt/PKB is the forkhead transcription factor, forkhead box protein of the subclass $\mathrm{O}$, member 1 (FoxO1, formerly referred to as FKHR; see Kaestner et al. 2000).
Forkhead transcription factors are implicated in a growing number of physiological processes, including apoptosis, cell cycle progression, and insulin signaling (Nakae et al. 1999, Tang et al. 1999, Nakamura et al. 2000, Alvarez et al. 2001). Phosphorylation of FoxO1 by Akt/PKB results in cytoplasmic, rather than nuclear localization, and inhibits function of this proapoptotic transcription factor, indicating post-translational regulation of FoxO1 activity (Nakae et al. 2000). Potential roles of FoxO1 in influencing ovarian functions are suggested by recent studies by Richards and colleagues (2002). Their findings indicate that FSH and insulin-like growth factor-I (IGF-I) both cause phosphorylation of FoxO1 in cultured granulosa cells (Richards et al. 2002). The ability of FSH and IGF-I to induce phosphorylation of FoxO1 is associated with translocation of protein from nucleus to cytoplasm, and suggests post-translational influences of these factors on as yet undefined activities of FoxO1 in the ovary. 
While phosphorylation represents one mechanism through which ovarian FoxO1 activity may be regulated, cell-specific expression and regulation of total FoxO1 protein levels also occurs in the ovary (Richards et al. 2002). Ovarian FoxO1 mRNA levels are regulated in a cell-specific manner, with FoxO1 mRNA levels increasing markedly during follicular development (Richards et al. 2002). These findings are perhaps surprising, given previous observations that indicate inhibitory effects of forkhead transcription factors on cell proliferation (Alvarez et al. 2001). However, it is not clear if the pattern of FoxO1 gene expression at the transcriptional level correlates well with FoxO1 protein levels, as no similar studies on FoxO1 protein localization have been reported. Furthermore, the relationship between FoxO1 protein levels and the onset of follicular atresia is not clear. Therefore, the present study utilized immunohistochemical methods to examine the cell-specific localization and regulation of FoxO1 protein levels during postnatal ovarian development, as well as gonadotropin-induced follicular development, ovulation, atresia and luteinization in immature female rats. In addition, we also compared ovarian FoxO1 localization in healthy preovulatory follicles of proestrous females to that in postnatal rat ovaries, and in cystic follicles of middle-aged acyclic, persistent estrous rats.

\section{Materials and Methods}

\section{Animals}

Intact, immature Sprague-Dawley rats (21 days old; Harlan Sprague-Dawley, Indianapolis, IN, USA) and young (4 months old) and middle-aged ( 9 months old) Long-Evans retired breeder females (Charles River Laboratories, Wilmington, MA, USA) were obtained from the commercial suppliers indicated. In addition, neonatal rats were obtained by mating of young Long-Evans males and females. Animals were maintained under a 16-h light, 8-h darkness schedule with food and water available ad libitum. Animals were treated in accordance with the NIH Guide for the Care and Use of Laboratory Animals. All protocols had the approval of the Institutional Animal Care and Use Committee, California State University, Los Angeles.

Immature rats received a subcutaneous injection of equine chorionic gonadotropin (eCG; $10 \mathrm{IU}$ ), followed $52 \mathrm{~h}$ later by an ovulatory dose (30 IU) of human chorionic gonadotropin (hCG). Ovaries were obtained at 0,24 and $52 \mathrm{~h}$ after eCG, and at 4,24 and $72 \mathrm{~h}$ after hCG. One ovary was fixed in $4 \%$ paraformaldehyde and processed for immunohistochemical analysis. The remaining ovary was snap-frozen and used for protein extraction and subsequent immunoblot analysis. Similarly, ovaries were collected from neonatal rats at 5, 10, and 25 days of age for immunohistochemical analysis (day of birth is day
1). Estrous cycle patterns were monitored in young and middle-aged Long-Evans female rats. Animals displaying at least 3 consecutive 4-day-long cycles were considered regularly cyclic, while those displaying at least 15 consecutive days of vaginal cornification were considered to be persistently estrous (PE). Ovaries were obtained at approximately $1000 \mathrm{~h}$ on the morning of proestrus (young regularly cyclic rats) and from acyclic PE females, fixed in $4 \%$ paraformaldehyde, and processed for immunohistochemical analyses of FoxO1 protein levels.

\section{Immunohistochemistry}

After fixation, ovaries were embedded in paraffin and $8 \mu \mathrm{m}$ sections were cut and mounted on slides. The sections were then processed for immunohistochemical analysis using standard procedures (Shi et al. 2000). Sections were incubated for $16 \mathrm{~h}$ at room temperature with a polyclonal sheep immunoaffinity purified antiserum directed against the full length FoxO1 protein $(0.5 \mu \mathrm{g} / \mathrm{ml}$ IgG; Upstate Cell Signaling Solutions, Waltham, MA, USA). Sections were then incubated in a biotinylated rabbit anti-sheep IgG secondary antibody (diluted 1:1000 in $10 \mathrm{mM}$ sodium phosphate, $\mathrm{pH} 7 \cdot 4$ containing $0 \cdot 9 \%$ saline and 1\% BSA; Vector Labs, Inc, Burlingame, CA, USA), incubated at room temperature for $1 \mathrm{~h}$. FoxO1 immunoreactivity was then visualized using the $\mathrm{ABC}$ Kit Elite (Vector Labs Inc., Burlingame, CA, USA) and 0.05\% 3,3'-diaminobenzidine tetrachloride (DAB; Sigma Chemical Co., St Louis, MO, USA) in $10 \mathrm{mM}$ PBSbuffered saline containing $0 \cdot 01 \% \mathrm{H}_{2} \mathrm{O}_{2}$, using a 5-min incubation. Specificity of the antibody was examined using normal sheep serum instead of primary antibody. To identify structural components and cell types within the ovary, the section was counter-stained with hematoxylin. Relative levels of immunostaining between groups and cell types were evaluated by two independent observers, with at least four ovaries examined per group/time point. Only samples processed at the same time were compared with one another. Results described represent consistently observed patterns of immunostaining.

\section{Immunoblot analysis}

Whole ovary protein from gonadotropin-treated rats was extracted using radioimmunoprecipitation (RIPA) lysis buffer $(50 \mathrm{mM}$ Tris $-\mathrm{HCl}$, pH 8.0 containing $0 \cdot 15 \mathrm{M}$ $\mathrm{NaCl}, 0 \cdot 5 \%$ nonidet $\mathrm{P} 40,20 \%$ glycerol, $25 \mathrm{mM}$ benzamidine, $0.5 \mu \mathrm{g} / \mathrm{ml}$ leupeptine, $0.7 \mu \mathrm{g} / \mathrm{ml}$ pepstanin A, $10 \mu \mathrm{g} / \mathrm{ml}$ trypsin inhibitor and $2 \mu \mathrm{g} / \mathrm{ml}$ aprotinin) in a Dounce homogenizer. After homogenization, samples were incubated for $30 \mathrm{~min}$ on ice, vortexed, and centrifuged for $5 \mathrm{~min}$ at $14000 \mathrm{~g}$. The supernatant was separated and protein concentration was determined by a modification of the Bradford method (Biorad Laboratories, Hercules, CA, USA) using BSA standards and microplate 
absorbance readings at $595 \mathrm{~nm}$. Determination of FoxO1 protein levels was performed by immunoblot analysis. Briefly, the proteins were resolved by $7 \cdot 5 \%$ polyacrylamide SDS gel electrophoresis under reducing conditions. In each experiment, equal quantities of protein $(20 \mu \mathrm{g})$ were loaded for each sample. Protein was then transferred electrophoretically from the gel onto nitrocellulose membranes. Filters were blocked with 5\% milk in TBST (Tris buffered saline with $0.05 \%$ Tween 20), followed by washing and incubation with the polyclonal sheep immunoaffinity purified antiserum against FoxO1 (1:1000 dilution in TBST containing 1\% BSA, incubated for $16 \mathrm{~h}$ at $4{ }^{\circ} \mathrm{C}$ ). Blots were then washed and incubated at room temperature for one hour with a 1:25000 dilution of horseradish peroxidase-conjugated polyclonal rabbit antisheep IgG secondary antibody (Pierce Biotechnology, Rockford, IL, USA). After washing in TBST, membranes were incubated in a luminol/enhancer-stable peroxide substrate solution (Pierce Biotechnology) at room temperature for 5-15 min to allow chemiluminescent detection of signals, and blots were then used to expose X-ray film. Resulting autoradiograms were then digitally analyzed using a computerized image analysis system (ImagePC, Scion Corp, Frederick, MD, USA), and the results were subjected to one-way analysis of variance, followed by Tukey's post-hoc test to determine which groups differed significantly. A confidence level of $P<0 \cdot 05$ was considered statistically significant.

\section{Results}

FoxO1 immunoreactivity during postnatal ovarian follicle development and luteinization

To examine the relationship between postnatal follicular growth and FoxO1 expression, we collected ovaries from neonatal rats at 5, 10, and 25 days of age. Ovaries of five-day-old females contained only primordial follicles, while those of 10-day-old rats contained primordial, primary, and small secondary follicles (Fig. 1A and B respectively). In these early stages of follicular development, FoxO1 immunoreactivity in the ovary was very faint in granulosa cells. In contrast, by 25 days of age follicles had reached the small and medium antral stages (up to $460 \mu \mathrm{m}$ in diameter; Fig. 1C) and exhibited high levels of FoxO1 staining in granulosa, but not thecal or stromal cells. Specificity of immunoreactivity was confirmed by the use of normal sheep serum (NSS) in place of primary antibody, which resulted in the absence of reaction product (see Fig. 2F).

\section{FoxO1 immunoreactivity during ovarian follicle development, atresia, and luteinization in gonadotropin-primed immature rats}

We next determined whether the levels of FoxO1 protein were regulated in granulosa cells during gonadotropin-

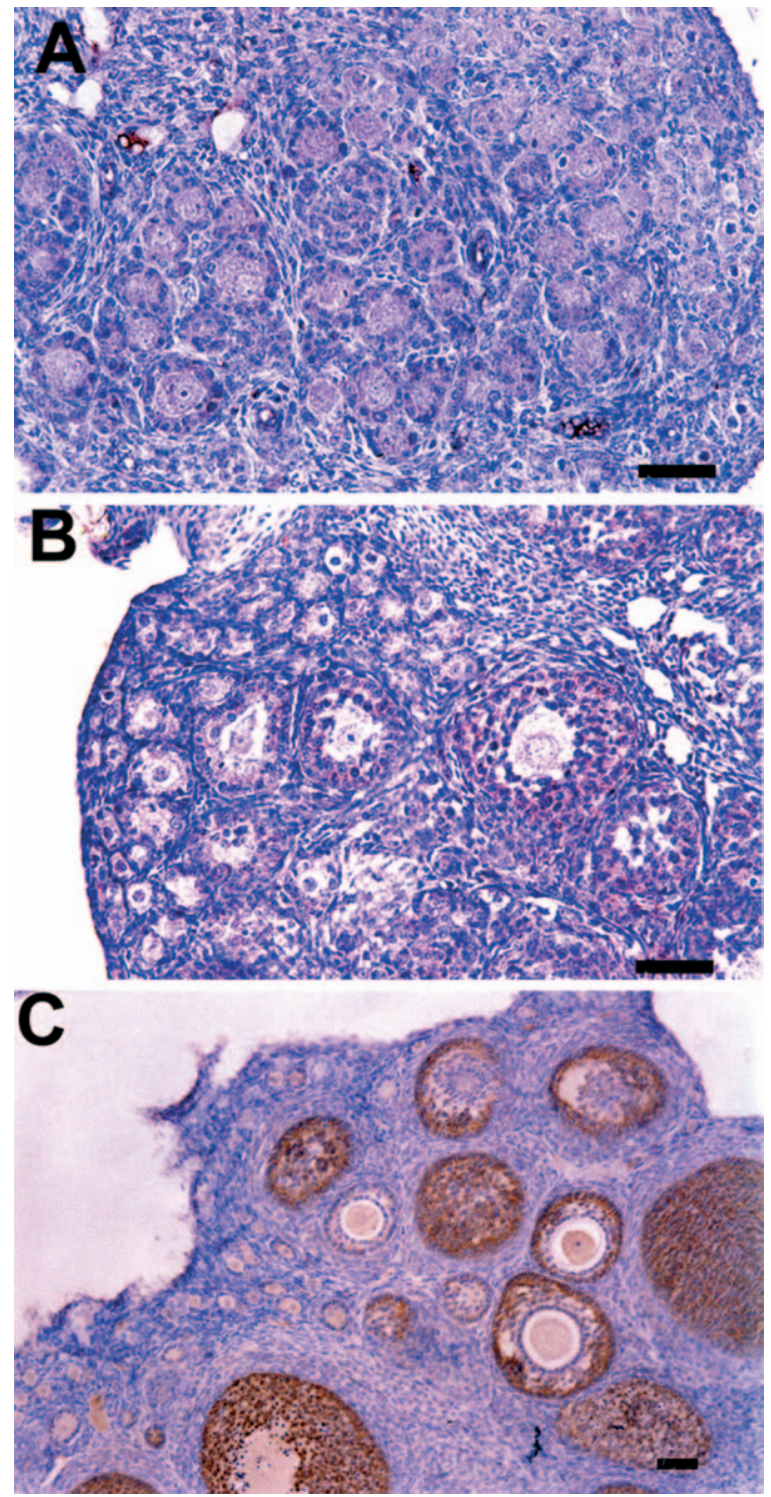

Figure 1 Immunohistochemical localization of FoxO1 protein in ovaries of neonatal and immature rats. Ovaries were collected from rats at day 5 (A), day 10 (B) and at 25 days of age (C). Ovarian sections were prepared for immunohistochemistry and FoxO1 immunoreactivity was detected using a polyclonal sheep immunoaffinity purified antiserum directed against the FoxO1 protein. Positive immunostaining for FoxO1 is indicated by a brown reaction product. Note the very faint FoxO1 immunoreactivity in ovaries obtained from rats at 5 and 10 days of age, compared with the strong FoxO1 staining in granulosa cells of developing follicles at 25 days of age. Bar $=50 \mu \mathrm{m}$.

induced follicular development, atresia and luteinization in immature rats. Prior to gonadotropin treatment, FoxO1 immunoreactivity was strong in the granulosa layer of healthy preantral, small antral, and large antral follicles (Figs 2A and 3A). Within the granulosa layer, however, 

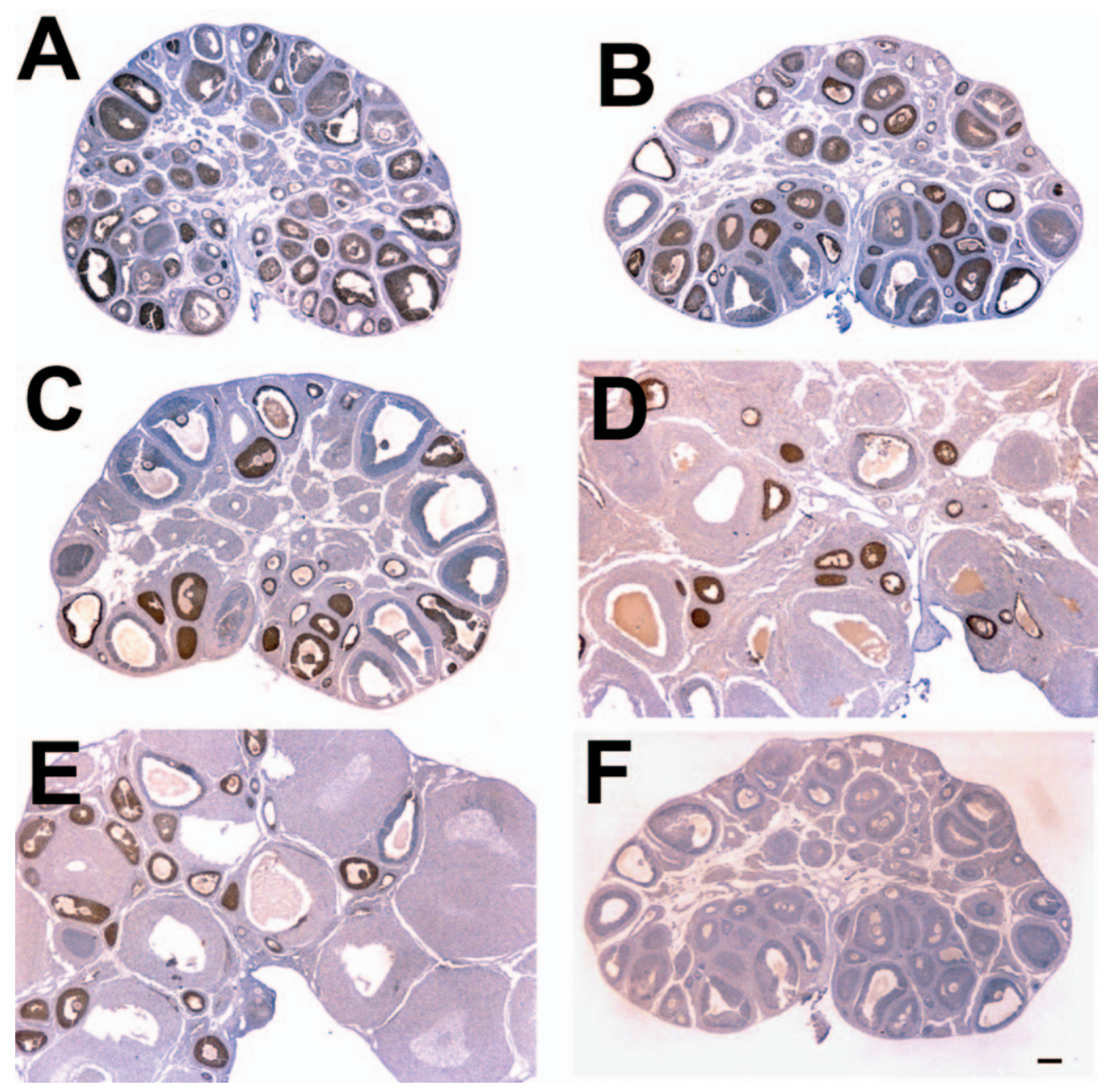

Figure 2 Ovarian localization of FoxO1 protein levels during gonadotropin-induced follicular development, ovulation, and luteinization in immature female rats. FoxO1 immunoreactivity was low in theca cells but high in granulosa cells of small and medium antral follicles at 0 and $24 \mathrm{~h}$ after eCG (A and B respectively). However, FoxO1 levels were minimal in larger antral follicles $(B, C)$ and in preovulatory follicles $52 \mathrm{~h}$ after eCG (C). In addition, FoxO1 levels were very low in corpora lutea at $24 \mathrm{~h}$ (D) and $72 \mathrm{~h}(\mathrm{E})$ after receiving an ovulatory dose of hCG. In control experiments, no significant immunoreactivity was observed when normal sheep serum was used instead of primary antibody (F). Bar $=200 \mu \mathrm{m}$.

FoxO1 staining was heterogeneous, being low in the layer of granulosa cells immediately surrounding the oocyte, but high in the remaining granulosa cells (Fig. 3E). This heterogeneous pattern was consistently observed from preantral to small antral follicles $(100-350 \mu \mathrm{m})$, but less evident in larger antral follicles. At $24 \mathrm{~h}$ after eCG, FoxO1 levels were decreased in granulosa cells of healthy large antral follicles (Figs $2 \mathrm{~B}$ and $3 \mathrm{~B}$ ). By $52 \mathrm{~h}$ after eCG, FoxO1 immunoreactivity in preovulatory follicles remained low, although staining was evident in cumulus cells and in a thin layer of antral granulosa cells (see Figs $2 \mathrm{C}$ and $3 \mathrm{C}$ ). At this same time point, FoxO1 levels remained high in the granulosa layer of follicles at smaller stages of development (Fig. 2C). Subsequently, during gonadotropin-induced ovulation and luteinization, FoxO1 immunoreactivity was not detected in developing corpora lutea at 24 and $72 \mathrm{~h}$ after an ovulatory dose of hCG (Figs 2D, E and 3D). However, FoxO1 was expressed in granulosa cells of developing follicles at those same time points.

During gonadotropin-induced follicle development, strong FoxO1 immunoreactivity was consistently observed in granulosa cells of follicles undergoing atresia. In such follicles, the cellular localization of FoxO1 appeared to be primarily nuclear, obscuring hematoxylin-stained nuclei (Fig. 3F). In contrast, FoxO1 localization in granulosa cells of neighboring healthy follicles appeared to be primarily cytoplasmic, with clearly visible nuclei (Fig. 3F). 


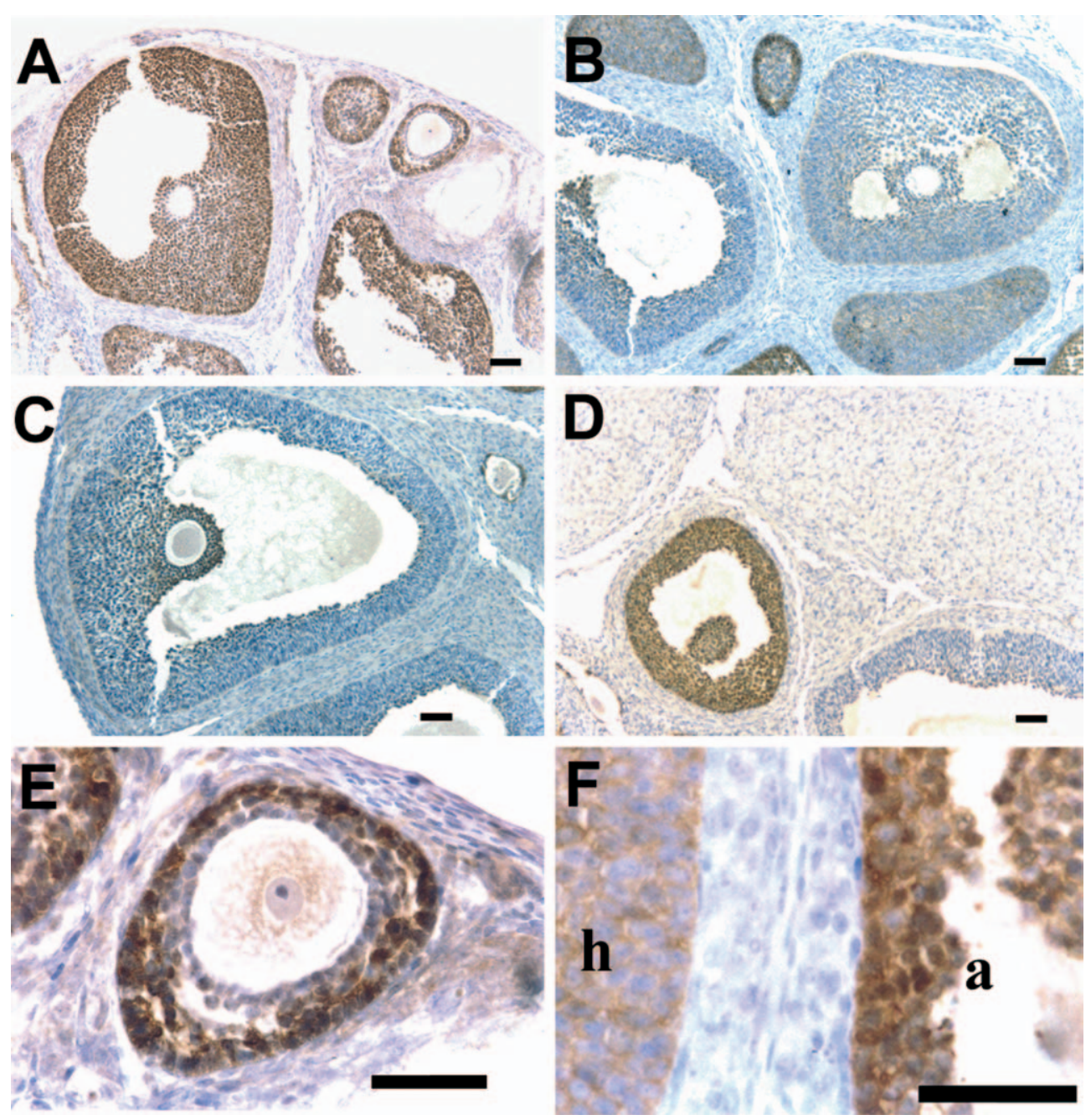

Figure 3 Higher magnification views of FoxO1 immunoreactivity in developing follicles and corpora lutea of gonadotropin-treated immature rats. Prior to eCG treatment, FoxO1 protein levels were high in small, medium, and large developing follicles (A). However, $24 \mathrm{~h}$ after eCG, FoxO1 staining remained high in smaller follicles, but was decreased in larger follicles (B). At $52 \mathrm{~h}$ after eCG, FoxO1 immunoreactivity in preovulatory follicles was limited to cumulus cells and the most antral layer of granulosa (C). At $72 \mathrm{~h}$ after an ovulatory dose of hCG, FoxO1 staining was absent in corpora lutea, but strong in follicles undergoing atresia (D). In small developing follicles, the granulosa layer nearest the oocyte was typically devoid of FoxO1 staining (E). While FoxO1 localization in granulosa cells of healthy developing follicles (h) was primarily cytoplasmic, that in atretic follicles (a) was primarily nuclear (F). Bar $=50 \mu \mathrm{m}$.

Immunoblot analysis of FoxO1 protein during ovarian follicle development and luteinization

Western blot analysis of FoxO1 protein levels was performed following gel fractionation of ovarian protein extracts obtained from immature female rats treated with eCG and hCG, as in Figs 2 and 3 above. Using the FoxO1 antiserum, a band with an apparent molecular mass of approximately $75 \mathrm{kDa}$ was identified (Fig. 4), consistent with previous reports (Durham et al. 1999). Whole ovarian FoxO1 levels were readily detectable between 0 and $52 \mathrm{~h}$ of eCG treatment. Subsequently, whole ovarian FoxO1 protein levels decreased to very low levels by 24 and $72 \mathrm{~h}$ after hCG, indicating down-regulation of FoxO1 in the luteal ovary.

Autoradiograms were subjected to digital image analysis to provide a more quantitative evaluation of ovarian FoxO1 protein levels during gonadotropin treatments (Fig. 5). Relative levels of FoxO1 in whole ovarian homogenates were highest prior to and $24 \mathrm{~h}$ after eCG administration, and decreased significantly $(P<0 \cdot 001)$ by $52 \mathrm{~h}$ after eCG treatment. A further decline $(P<0 \cdot 001)$ in FoxO1 levels was evident at $24 \mathrm{~h}$ after administration of hCG, with these lower levels persisting at $72 \mathrm{~h}$ after hCG. 
eCG

\section{4

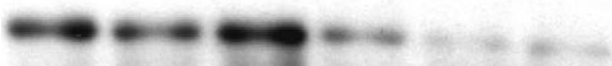 \\ $-81 \mathrm{kD}$}

Figure 4 Immunoblot analysis of total FoxO1 levels in whole ovarian extracts of immature rats treated with eCG to stimulate follicular development, followed by an ovulatory dose of hCG $52 \mathrm{~h}$ later to induce ovulation and luteinization. Ovaries were obtained at various times following treatment with eCG $(0,24$, and $52 \mathrm{~h})$ or eCG followed by hCG $(4,24$, and $72 \mathrm{~h}$ after hCG). The migration position of an $81 \mathrm{kDa}$ standard is indicated. Note the marked decline in whole ovarian FoxO1 levels observed following hCG-induced ovulation and luteinization.

FoxO1 levels in preovulatory follicles versus cystic follicles of middle-aged female rats

The high levels of FoxO1 expression in atretic follicles in ovaries of immature rats is consistent with the proapoptotic function of this transcription factor. To further examine the relationship between FoxO1 levels and cell survival, we performed immunohistochemical comparisons of FoxO1 immunoreactivity in healthy preovulatory follicles of young proestrous rats versus developing and established cystic follicles of middle-aged acyclic, PE rats respectively. FoxO1 levels were low in granulosa cells of healthy preovulatory follicles $(900 \mu \mathrm{m}$ in diameter) of cyclic rats, with immunoreactivity limited to cumulus and antral granulosa cells (Fig. 6A). In PE ovaries, however, developing cystic follicles undergoing atresia exhibited high levels of FoxO1 in the entire granulosa layer (Fig. 6B,C;

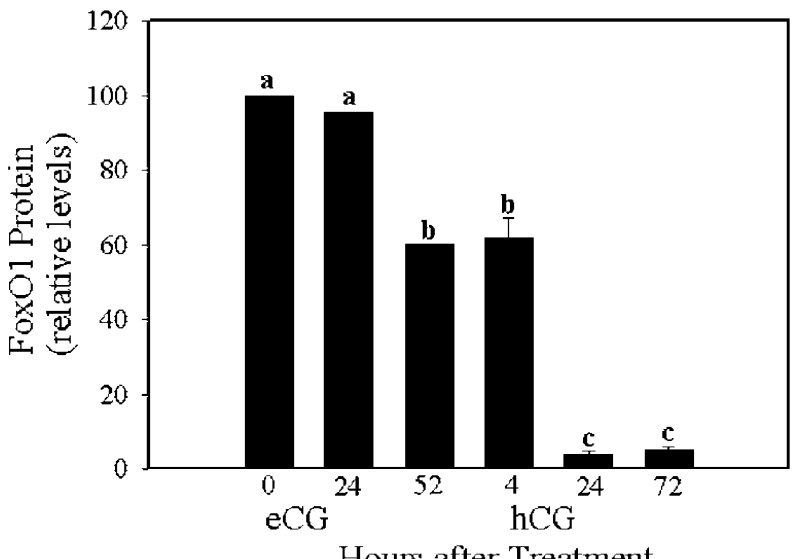

Hours after Treatment

Figure 5 Influence of gonadotropin treatments on FoxO1 immunoreactivity in whole ovarian homogenates. Immature rats were treated with eCG followed $52 \mathrm{~h}$ later by an ovulatory dose of hCG, as in Fig. 4. Following immunoblot analysis, the intensity of FoxO1 immunoreactive bands was determined by digital image analysis, and expressed relative to the eCG time 0 group. Differing letters above the bars indicate a statistically significant difference between the groups; $n=4$ /group, except for the hCG $4 \mathrm{~h}$ time point, for which $n=2$.
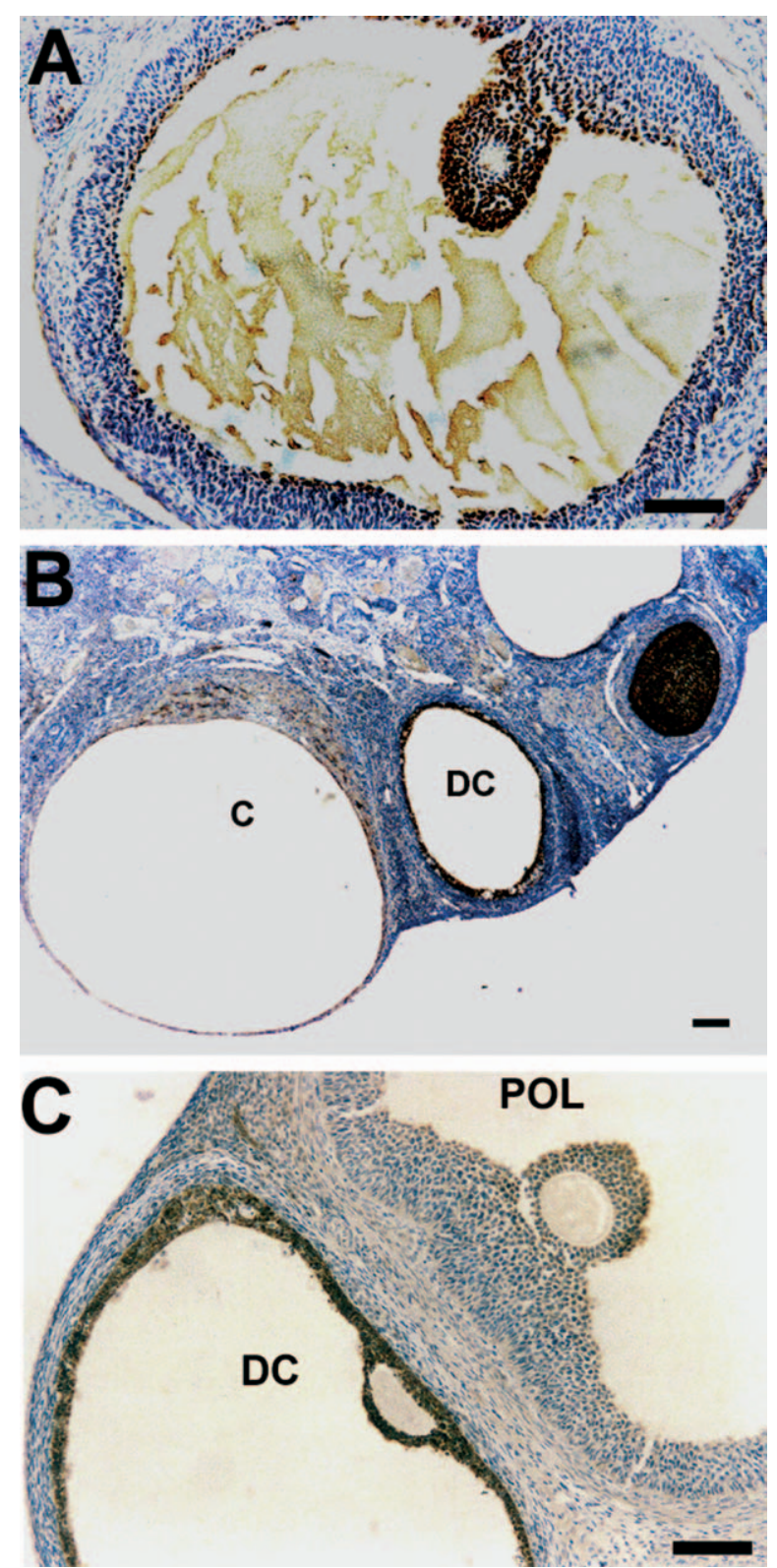

Figure 6 Immunohistochemical comparison of FoxO1 immunoreactivity in a healthy preovulatory-like follicle from a young proestrous female (A), developing cystic (DC) and established cystic $(C)$ follicles in the ovary of a middle-aged (9 months old) acyclic, persistent-estrous rat (B), and developing cystic (DC) and preovulatory-like (POL) follicles of a persistent-estrous rat (C). In preovulatory (A) and preovulatory-like (C) follicles, FoxO1 was limited to antral granulosa and cumulus cells, as observed in immature, gonadotropin-treated females. However, developing cystic follicles undergoing atresia exhibited high levels of FoxO1 in the granulosa layer (B, C). In fully formed cystic follicles, the granulosa layer was thin or non existent and exhibited less FoxO1 immunoreactivity than follicles developing into cysts (B). Bar $=100 \mu \mathrm{m}$. 
follicles labeled DC). In fully formed cystic follicles, the granulosa layer was thin or non existent, and subsequently little FoxO1 immunoreactivity was observed (Fig. 6B; follicle labeled C). Small numbers of preovulatory-like follicles could be observed in PE rats, with patterns of FoxO1 expression (limited to cumulus and antral granulosa cells) similar to that in preovulatory follicles of immature gonadotropin-treated and young cyclic females (Fig. 6C; follicle labeled POL).

\section{Discussion}

Findings from the present study demonstrate the regulated, cell-specific localization of FoxO1 protein in the ovaries of neonatal, immature gonadotropin-treated, and adult rats. While much attention has focused on the role of Akt/PKB in post-translational regulation of forkhead transcription factor activities, the present studies and others (Richards et al. 2002) demonstrate that ovarian FoxO1 expression is regulated in a highly cell-specific manner. The presence of FoxO1 immunostaining in granulosa, but not stromal, thecal, or healthy luteal cells is consistent with previous findings on FoxO1 message levels (Richards et al. 2002). While the exact roles of this transcription factor in the ovary are not known, the highly regulated pattern of localization likely reflects important actions of FoxO1 on ovarian functions such as follicle growth, differentiation, and/or atresia, and may indicate influences on and/or regulation by the oocyte. Furthermore, data from the present study reveal additional complexity in the regulation of FoxO1 expression, in that there is apparently a high degree of translational and/or post-translational control of protein levels.

The differential pattern of FoxO1 expression in different ovarian cells may provide insight into the functional role(s) of FoxO1 in granulosa cells. In nongonadal cells, it is clear that FoxO1 is a proapoptotic transcription factor (Tang et al. 1999, Nakamura et al. 2000). The high level of FoxO1 we observed in apoptotic granulosa cells but not theca cells of atretic follicles and developing cysts may coincide and contribute to observed differences in the onset and mechanisms controlling apoptosis in these cell types (Tilly et al. 1992, Palumbo \& Yeh 1994, Porter et al. 2001). Significantly, while the subcellular distribution of FoxO1 protein in healthy granulosa cells was primarily cytoplasmic, that in granulosa cells of atretic follicles was predominantly nuclear (see Fig. 3F). This nuclear staining corresponds to the functional localization of FoxO1 as a proapoptotic transcription factor (Nakae et al. 2000), indicating a causal relationship between follicular atresia and increased nuclear FoxO1 protein levels. The decreased levels of FoxO1 in the luteal ovary observed by immunohistochemistry and immunoblot analyses are consistent with a previous report on FoxO1 message (Richards et al. 2002). Since the present study did not include analysis of regressing corpora lutea, it is not known whether levels of FoxO1, or other forkhead transcription factors (such as FoxO3a and FoxO4) increase in luteal cells during luteal demise.

The presence of FoxO1 in granulosa cells of small antral follicles, but not in those in large follicles, theca cells or luteal cells, may also reflect the functionally undifferentiated state of granulosa cells in small follicles, suggesting that FoxO1 is down-regulated during gonadotropininduced cell maturation. Consistent with this hypothesis, both FSH and IGF-I, factors that augment granulosa cell differentiation, act post-translationally to phosphorylate FoxO1 (Richards et al. 2002), resulting in cytoplasmic localization and, presumably, loss of transcriptional activity. Together, the decrease in protein content and post-translational inhibition of protein activity induced by FSH suggest that decreased FoxO1 activity is an important step in gonadotropin-induced granulosa cell differentiation. However, in stark contrast, FoxO1 mRNA and protein levels are induced by cAMP analogs in human endometrial stromal cells, and FoxO1 interacts with the CCAAT/enhancer-binding protein beta to facilitate protein kinase A-dependent gene expression during differentiation (Christian et al. 2002). In these endometrial cells, treatment with cAMP results in nuclear, rather than cytoplasmic localization of FoxO1 (Christian et al. 2002). It is thus clear that regulation of FoxO1 expression and action is complex, and highly tissue-specific. Further studies are required to elucidate any role of FoxO1 in the modulation of ovarian cell differentiation.

The dynamic regulation of FoxO1 in granulosa cells during follicular development may further suggest roles of this transcription factor in the regulation of granulosa cell proliferation. During initial stages of gonadotropinindependent growth, granulosa cells of small preantral follicles exhibit low levels of FoxO1, as is evident in early postnatal ovaries (Fig. 1A,B). However, FoxO1 immunoreactivity is higher in granulosa cells of larger preantral and small antral follicles, containing oocytes of increased size, at 25 days of age, prior to treatment with eCG (Fig. 1C; note change in scale). Interestingly, treatment with gonadotropin to stimulate further follicular growth resulted in a marked down-regulation of granulosa FoxO1 levels. In this regard, forkhead transcription factors reportedly inhibit cell cycle progression, via increased levels of the cell-cycle inhibitor p27 kip1 (Medema et al. 2000) and down-regulation of cyclin B (Alvarez et al. 2001). In this regard, cyclin B and p27 kip1 have been implicated in the hormonal regulation of granulosa cell proliferation (Chaffin et al. 2001). Surprisingly, the down-regulation of FoxO1 protein content that we observed in developing follicles is not accompanied by a decline in follicular FoxO1 mRNA levels (Richards et al. 2002). This indicates that the regulation of FoxO1 protein levels during follicular development is mediated not only by transcriptional regulation of mRNA levels, but also by translational and/or posttranslational mechanisms. 
The regulation of FoxO1 protein levels differed markedly within the granulosa layer at various stages of development. In preantral and small antral follicles, FoxO1 was expressed throughout the granulosa compartment, with the distinct exception of the single layer of granulosa cells immediately surrounding the oocyte (see Fig. 3E). In contrast, in larger developing and preovulatory follicles, the granulosa layer was devoid of FoxO1 immunoreactivity, with the exception of the cumulus and most of the antral granulosa layer (Fig. 3C). The functional significance of this heterogeneous distribution of FoxO1 protein within the granulosa compartment is not clear. It is well recognized, however, that the oocyte produces factors that influence gene expression in neighboring granulosa cells (Elvin et al. 1999, Joyce et al. 1999, 2001), providing a basis for observed differences between mural and cumulus cell expression. However, a potential basis for differences in FoxO1 expression between mural and the most antral layer of granulosa cells is less apparent. Further studies are clearly required to understand the heterogeneous pattern of FoxO1 expression observed within the granulosa layer.

While FoxO1 expression is decreased in the granulosa layer of healthy preovulatory follicles, the absence of an ovulatory gonadotropin surge in acyclic middle-aged PE rats results in the formation of follicular cysts. PE females display follicular growth, but preovulatory follicles fail to ovulate due to impaired neuroendocrine control of luteinizing hormone secretion (Anzalone et al. 1998, Chern et al. 2000, LaPolt \& Lu 2001). Thus, as observed in this study, ovaries of PE rats may contain healthy Graafian (or preovulatory-like) follicles (Fig. 6C). However, these fail to ovulate due to the absence of normal neuroendocrine function, resulting in the formation and accumulation of follicular cysts with degenerating granulosa layers. Healthy preovulatory-like follicles of PE females exhibited the same pattern of low FoxO1 expression in the granulosa layer as preovulatory follicles in immature gonadotropin-treated (Fig. 2C) and young proestrous rats (Fig. 6A). However, FoxO1 immunoreactivity was increased in the granulosa layer of unovulated follicles developing into cysts, presumably reflecting the reported role of FoxO1 in the induction of apoptosis (Datta et al. 1999, Tang et al. 1999, Nakae et al. 2000, Burgering \& Kops 2002). As cyst development progressed, the granulosa layer became thin or nonexistent, and FoxO1 immunoreactivity was lower than that in developing cysts. These temporal changes in FoxO1 protein levels strengthen the proposed role of FoxO1 as a mediator of apoptosis in granulosa cells. Furthermore, the dynamic regulation of granulosa cell FoxO1 levels as follicles progress from small antral (high, primarily cytoplasmic FoxO1 levels) to healthy preovulatory follicles (FoxO1 immunoreactivity restricted to cumulus and antral granulosa cells) to an atretic, cystic state (high, primarily nuclear staining) likely reflects multiple functions and complex regulation of this forkhead transcription factor in the ovary.
Future studies are required to reveal the molecular mechanisms regulating FoxO1 protein levels and activity, and the various influences of FoxO1 on ovarian function.

\section{Funding}

This work was supported by the National Institutes of Health MBRS SCORE Program grant GM08101 (to P S L).

\section{References}

Alvarez B, Martinez-A C, Burgering BM \& Carrera AC 2001 Forkhead transcription factors contribute to execution of the mitotic programme in mammals. Nature 413 744-747.

Anzalone CR, Lu JK \& LaPolt PS 1998 Influences of age and reproductive status on ovarian ovulatory responsiveness to gonadotropin stimulation. Proceedings of the Society for Experimental Biology and Medicine 217 455-460.

Burgering BMT \& Kops GJPL 2002 Cell cycle and death control: long live forkhead. Trends in Biochemical Sciences 27 352-360.

Chaffin CL, Schwinof KM \& Stouffer RL 2001 Gonadotropin and steroid control of granulosa cell proliferation during the periovulatory interval in rhesus monkeys. Biology of Reproduction 65 755-762.

Chern BY, Chen YH, Hong LS \& LaPolt PS 2000 Ovarian steroidogenic responsiveness to exogenous gonadotropin stimulation in young and middle-aged female rats. Proceedings of the Society for Experimental Biology and Medicine 224 285-291.

Christian M, Zhang X, Schneider-Merck T, Unterman TG, Gellersen B, White JO \& Brosens JJ 2002 Cyclic AMP-induced forkhead transcription factor, FKHR, cooperates with CCAAT/enhancerbinding protein beta in differentiating human endometrial stromal cells. Journal of Biological Chemistry 277 20825-20832.

Datta SR, Brunet A \& Greenberg ME 1999 Cellular survival: a play in three Akts. Gene and Development 13 2905-2927.

Durham SK, Suwanichkul A, Scheimann AO, Yee D, Jackson JG, Barr FG \& Powell DR 1999 FKHR binds the insulin response element in the insulin-like growth factor binding protein-1 promoter. Endocrinology 140 3140-3146.

Elvin JA, Clark AT, Wang P, Wolfman NM \& Matzuk MM 1999 Paracrine actions of growth differentiation factor-9 in the mammalian ovary. Molecular Endocrinology 13 1035-1048.

Gonzalez-Robayna IJ, Falender AE, Ochsner S, Firestone GL \& Richards JS 2000 Follicle-stimulating hormone (FSH) stimulates phosphorylation and activation of protein kinase $\mathrm{B}(\mathrm{PKB} / \mathrm{Akt})$ and serum and glucocorticoid-induced kinase (Sgk): evidence for A kinase-independent signaling by FSH in granulosa cells. Molecular Endocrinology 14 1283-1300.

Joyce IM, Pendola FL, Wigglesworth K \& Eppig JJ 1999 Oocyte regulation of kit ligand expression in mouse ovarian follicles. Developmental Biology 214 342-353.

Joyce IM, Pendola FL, O’Brien M \& Eppig JJ 2001 Regulation of prostaglandin-endoperoxide synthase 2 messenger ribonucleic acid expression in mouse granulosa cells during ovulation. Endocrinology 142 3187-3197.

Kaestner KH, Knochel W \& Martinez DE 2000 Unified nomenclature for the winged helix/forkhead transcription factors. Genes and Development 14 142-146.

LaPolt PS \& Lu JK 2001 Effects of aging on luteinizing hormone secretion, ovulation, and ovarian tissue-type plasminogen activator expression. Experimental Biology and Medicine 226 127-132.

Medema R H, Kops GJ, Bos JL \& Burgering BM 2000 AFX-like forkhead transcription factors mediate cell-cycle regulation by $\mathrm{R}$ as and PKB through p27 kip. Nature 404 782-787. 
Nakae J, Park BC \& Accili D 1999 Insulin stimulates phosphorylation of the forkhead transcription factor FKHR on serine 253 through a Wortmannin-sensitive pathway. Journal of Biological Chemistry 274 15982-15985.

Nakae J, Barr V \& Accili D 2000 Differential regulation of gene expression by insulin and IGF-1 receptors correlates with phosphorylation of a single amino acid residue in the forkhead transcription factor FKHR. EMBO Journal 19 989-996.

Nakamura N, Ramaswamy S, Vazquez F, Signoretti S, Loda M \& Sellers WR 2000 Forkhead transcription factors are critical effectors of cell death and cell cycle arrest downstream of PTEN. Molecular and Cellular Biology 20 8969-8982.

Palumbo A \& Yeh J 1994 In situ localization of apoptosis in the rat ovary during follicular atresia. Biology of Reproduction $\mathbf{5 1}$ 888-895.

Porter DA, Harman RM, Cowan RG \& Quirk SM 2001 Susceptibility of ovarian granulosa cells to apoptosis differs in cells isolated before or after the preovulatory LH surge. Molecular and Cellular Endocrinology 176 13-20.
Richards JS, Sharma SC, Falender AE \& Lo YH 2002 Expression of FKHR, FKHRL1, and AFX genes in the rodent ovary: evidence for regulation by IGF-I, estrogen, and the gonadotropins. Molecular Endocrinology 16 580-599.

Shi F, Watanabe G, Trewin AL, Hutz RJ \& Taya K 2000 Localization of inhibin/activin subunits in follicular dominance during the estrous cycle of guinea pigs. Zoological Science $\mathbf{1 7}$ $1311-1320$.

Tang ED, Nunez G, Barr FG \& Guan KL 1999 Negative regulation of the forkhead transcription factor FKHR by Akt. Journal of Biological Chemistry 274 16741-16746.

Tilly JL, Kowalski KI, Schomberg DW \& Hsueh AJ 1992 Apoptosis in atretic ovarian follicles is associated with selective decreases in messenger ribonucleic acid transcripts for gonadotropin receptors and cytochrome P450 aromatase. Endocrinology 131 1670-1676.

Received 29 May 2003

Accepted 23 July 2003 